\title{
Indicadores de eficiencia relativa del proceso de gestión de crédito en un banco colombiano, mediante análisis envolvente de datos (DEA)*
}

doi:10.11144/Javeriana.cc17-43.ierp

\section{Sandra Paola Sánchez-Gooding}

Investigadora independiente. Magíster en administración.

Ingeniera industrial.

Correo electrónico: sapsanchezgo@unal.edu.co

\section{Gloria Isabel Rodríguez-Lozano}

Profesora asociada, Facultad de Ciencias Económicas,

Universidad Nacional de Colombia. PhD en ciencias

económicas. MSc, ingeniería industrial. Administradora

de empresas.

Correo electrónico: girodriguezl@unal.edu.co

\footnotetext{
* El presente artículo es producto de una investigación, el título del proyecto de investigación es: Estudio de la eficiencia y la productividad de los sectores de la economía colombiana. Universidad Nacional de Colombia, fecha de realización durante el año 2014 y hasta abril de 2015, código interno de registro: 11449
} 
Resumen El presente trabajo tiene como objetivo medir la eficiencia relativa de las unidades que participan en el proceso de gestión de crédito de un banco colombiano, mediante la utilización del análisis envolvente de datos (Data Envelopment Analysis, DEA). Mediante un doble proceso de optimización, esta metodología de programación lineal avanzada genera un único índice de eficiencia relativa para cada una de las unidades estudiadas, aunque es capaz de incluir múltiples recursos y múltiples salidas.

En el banco objeto de estudio, las actividades de crédito están organizadas en cinco bancas [unidades estratégicas de negocio que se especializan en tipos de productos y/o mercados objetivos; establecen sus propios planes tácticos; tienen un presupuesto específico asignado y son autónomas en la toma de decisiones comerciales y operacionales] de la siguiente manera: banca personal [crédito de consumo y libre inversión a personas]; banca agropecuaria [créditos para actividades agrícolas pecuarias, forestales, acuícolas y pesqueras]; banca de microfinanzas [para necesidades de familias, microempresarios y personas de bajos ingresos]; banca empresarial [satisface necesidades de empresas] y banca oficial [dirigida en general a las empresas del sector oficial]. A su vez, cada banca está dividida en ocho zonas geográficas: Antioquia, Bogotá, Cafetera, Costa, Occidente, Oriente, Santanderes y Sur, por lo cual, el objeto de estudio son cuarenta unidades. Se pretende dar respuesta a los siguientes interrogantes: ¿Qué bancas y zonas geográficas del banco fueron eficientes y cuáles ineficientes en lo que respecta al proceso de gestión de crédito durante 2013? ¿Cuál es la medida de esta ineficiencia? El modelo DEA utilizado es Variable Returns to Scale (VRS) orientado a salidas, con cuatro entradas y dos salidas, trabajando diferentes tipos de unidades. Los resultados indican que las bancas con mejor desempeño son la agropecuaria y la oficial, y las zonas geográficas más eficientes son Sur y Cafetera. Adicionalmente, la banca más ineficiente es la personal y la zona geográfica con el peor desempeño es la Costa.

Palabras clave Análisis envolvente de datos, DEA; eficiencia relativa; eficiencia bancaria

\section{Código JEL G21}

\section{Relative Efficiency Indicators of the Credit Management Process in a Colombian Bank by Means of Data Envelopment Analysis (DEA)}

Abstract The purpose of this work is to measure the relative efficiency of the units that take part in the credit management process in a Colombian bank by means of the use of Data Envelopment Analysis (DEA). Using a double optimization process, this advanced linear programming methodology generates a single relative efficiency index for each one of the units being studied, although it is capable of including multiple resources and multiple outputs. In the bank that was used as the object of this study, credit activities are organized in five banking groups [strategic business units specialized on a type of o product and/ or target markets. These units stablish their tactical plans, have a specific assigned budget, and have autonomy for the making of commercial and operational decisions] as follows: personal banking [consumer credit and bank loans to individuals]; agricultural banking [credits for farming, livestock, forestry, aquaculture, and fishing activities]; microfinance banking [for the needs of families, microentrepreneurs, and low income people]; corporate banking [meeting the needs of companies]; and official banking [aimed, in general terms, at the companies of the official sector]. In turn, each banking group is divided in eight geographical areas: Antioquia, Bogota, Coffee region, Coastal region, Western region, Santander departments region, and South region, thus yielding forty units as the object of this study. We aim to answer the following questions: Which banking groups and geographical areas of the bank were efficient and which were inefficient regarding the credit management process during 2013? What is the amount of this inefficiency? The DEA model used includes Variable Returns to Scale (VRS) aimed on outputs, with four inputs and two outputs, working different types of units. Results indicate that the banking groups with the best performan- 
ce are the agricultural and official, and the most efficient geographical areas are the South and Coffee regions. Additionally, the most inefficient banking group is personal banking and the geographical region with the worst performance was the Coastal region.

Keywords data envelopment analysis, DEA; relative efficiency; banking efficiency

\section{Indicadores de eficiência relativa do processo de gestão de crédito em um banco colombiano, mediante análise de envoltória de dados (DEA)}

\footnotetext{
Resumo O presente trabalho objetiva medir a eficiência relativa das unidades envolvidas no processo de gestão de crédito de um banco colombiano, mediante utilização da análise envoltória de dados (Data Envelopment Analysis, DEA). Mediante um duplo processo de otimização, esta metodologia de programação linear avançada gera um índice único de eficiência relativa para cada uma das unidades estudadas, ainda que capaz de incluir vários recursos e várias saídas.
}

No banco objeto de estudo, as atividades de crédito são organizadas em cinco bancas [unidades estratégicas de negócio especializadas em tipos de produto e/ou mercados-alvo; estabelecem seus próprios planos tácticos; tem orçamento específico assignado e são autónomas na tomada de decisões comerciais e operacionais] como a seguir: banca pessoal [crédito de consumo e livre investimento para pessoas]; banca agropecuária [créditos para atividades agrícolas pecuárias, florestais, aquícolas e pesqueiras]; banca de microfinanças [para necessidades de famílias, microempresários e pessoal de baixa renda]; banca empresarial [satisfaz necessidades de empresas] e banca oficial [dirigida em geral às empresas do setor oficial]. Por sua vez, cada banca está dividida em oito zonas geográficas: Antioquia, Bogotá, Cafetera, Costa, Occidente, Oriente, Santanderes e Sur, pelo qual, o objeto de estudo são quarenta unidades. Visa-se dar resposta para as seguintes questões: Quais bancas e zonas geográficas do banco foram eficientes e quais não no que diz respeito do processo de gestão de crédito durante 2013? Qual a medida de tal ineficiência? O modelo DEA utilizado foi Variable Returns to Scale (VRS) orientado a saídas, com quatro entradas e duas saídas, trabalhando diferentes tipos de unidades. Os resultados apontam que as bancas com melhor desempenho são agropecuária e oficial, e as zonas geográficas mais eficientes são Sur e Cafetera. Além disso, a banca mais ineficiente é a pessoal e a zona geográfica com o pior desempenho foi a Costa.

Palavras-chave Análise de envoltória de dados, DEA; eficiência relativa; eficiência bancária

\section{Introducción}

La presente investigación busca obtener indicadores de eficiencia relativa de las bancas y zonas geográficas que participan en el proceso de gestión de crédito de un banco colombiano, mediante la aplicación de la metodología análisis envolvente de datos (Data Envelopment Analysis, DEA), con el ánimo de que estos resultados coadyuven a optimizar el proceso de toma de decisiones de la alta dirección con el fin de mejorar la eficiencia y la productividad de la entidad, por medio del mejoramiento de la eficiencia y la productividad del proceso de gestión de crédito. Como resultado del proceso investigativo, se da respuesta a los siguientes interrogantes: ¿qué bancas y zonas geográficas del banco fueron eficientes y cuáles ineficientes en lo que respecta al proceso de gestión de crédito durante 2013?, ¿cuál es la medida de esta ineficiencia?

Las instituciones financieras cumplen un rol primordial en una economía, pues facilitan 
el flujo de fondos a personas naturales, personas jurídicas y al gobierno. Y aunque no se desconoce la importancia de la prestación de otros servicios financieros como oferta de seguros, administración de ahorros e inversiones, arrendamiento financiero, etc., la cartera de crédito es el mayor componente de los activos de los establecimientos de crédito (Banco de la República, 2014, p. 24). Esto indica que el principal destino de los fondos de un banco es el otorgamiento de créditos de diferente índole: de consumo, de vivienda, de vehículo, agropecuario, entre otros.

En el proceso de otorgamiento de préstamos, para un cliente actual o potencial, es fundamental que el desembolso se realice en el menor tiempo posible; por eso, los plazos de respuesta de un banco deben estar dentro de las expectativas del cliente y los estándares del mercado. Por esta razón, los establecimientos financieros deben optimizar su proceso de otorgamiento de crédito para alcanzar una mayor productividad y eficiencia, y asegurar su capacidad de ejecución.

Sobre el comportamiento del crédito, el reporte de la situación del crédito en Colombia (Banco de la República, 2013, p. 1) muestra que en el primer trimestre de 2013 la demanda de crédito percibida por los intermediarios financieros disminuyó para todo tipo de carteras (comercial, de consumo, vivienda y de microcrédito).

Los sectores con mayor acceso al crédito continuaron siendo la industria, los servicios, el comercio, las comunicaciones y los importadores, que presentaron mejores condiciones de rentabilidad y con los cuales los intermediarios financieros no tienen grandes problemas para identificar buenos clientes. En contraste, el sector agropecuario continuó siendo el de mayores restricciones en el acceso al crédito, por los problemas para identificar buenos clientes y menores condiciones de rentabilidad.

Lo anterior puede explicarse por una disminución de la demanda en todos los tamaños de empresa, la falta de capacidad de pago para poder otorgar un volumen mayor de créditos, la falta de información financiera acerca de nuevos clientes y la actuación prudencial de los establecimientos de crédito que se refleja en la colocación de recursos para asumir un menor riesgo, entre otras razones. Así mismo, las estadísticas del DANE muestran que en 2002 la participación porcentual del sector agropecuario (agricultura, ganadería, caza, silvicultura y pesca) en el PIB colombiano era de 8,5\%. A partir de este año, esta participación ha mostrado una tendencia a la baja hasta ubicarse en 6,2\% para 2013 (Departamento Administrativo Nacional de Estadística, DANE, 2014).

El banco objeto de este estudio es el principal aliado financiero de los sectores agropecuario, oficial y de microfinanzas, y el ejecutor de las políticas del gobierno que se accionan por medio del Ministerio de Agricultura, en cuanto al desarrollo competitivo, equitativo y sostenible de los procesos agropecuarios forestales, pesqueros y de desarrollo rural. Actualmente, financia actividades rurales, agrícolas, pecuarias, pesqueras, forestales y agroindustriales, por medio de sus 742 sucursales en el primer semestre de 2014, lo cual lo convertía en el banco con la red de oficinas más extensa del país, y con la mayor cobertura presencial del 
país que ofrece soluciones financieras especializadas en esa época (Banco Agrario de Colombia, 2014b).

Por su composición accionaria, el banco es una sociedad de economía mixta del orden nacional, anónima, sujeta al régimen de empresa industrial y comercial del Estado, vinculada al Ministerio de Agricultura y Desarrollo Rural y hace parte del Sistema Nacional de Crédito Agropecuario (Banco Agrario de Colombia, 2014a, p. 1). A diciembre de 2013, el banco sigue siendo el sexto banco más grande, por nivel de activos, en el sistema bancario con una participación de 4,94\%, lo que evidencia su crecimiento de 2009 a 2013 (Banco Agrario de Colombia, 2013b, p. 97).

El banco maneja un alto volumen de transacciones de la banca personal, empresarial y oficial y cumple un importante rol de fomento en actividades del sector rural al proveer financiación al sector agropecuario de proyectos que se caractericen por ser rentables, productivos y sostenibles; en cuanto a los servicios bancarios, también cumple un rol importante de fomento al prestarlos en zonas donde no hay otras instituciones financieras; los municipios que sean centros de influencia en zonas de alta actividad agropecuaria (Banco Agrario de Colombia, 2009, p. 3).

En cuanto a cartera y desembolsos, a diciembre de 2013 se realizaron desembolsos por $\$ 4,8$ billones, en 365.746 operaciones. Las bancas con mayor participación son la agropecuaria con $46,10 \%$ del valor desembolsado y $64,98 \%$ de la cartera, y la empresarial con $26,47 \%$ del valor desembolsado y $13,52 \%$ de la cartera total (Banco Agrario de Colombia, 2013b, p. 48). En participación de mercado, según el informe de responsabilidad social preparado por el banco (Banco Agrario de Colombia, 2009, p. 21), esta creció en 21,2\% el saldo de cartera total a noviembre de 2009 , en comparación con el 2,0\% registrado por el sistema financiero, lo que le permitió aumentar su participación en el mercado, al pasar de 3,9 a $4,6 \%$.

Sumado a lo anterior, el banco no cuenta con indicadores de eficiencia y productividad por banca y zona geográfica, que apoyen y guíen la toma de decisiones y que reflejen el desempeño real de cada una. Los indicadores de productividad se relacionan con los procesos comerciales ejecutados en las oficinas, cuya medición permite mejorar la gestión comercial y operativa en cada una de las regionales del banco (Banco Agrario de Colombia, 2013a, p. 7).

Bancas y zonas geográficas: en el banco objeto de estudio, las bancas son unidades estratégicas de negocio que se especializan en productos y/o mercados objetivos. Establecen sus propios planes tácticos (alineados con el plan estratégico del banco), tienen un presupuesto específico asignado y son autónomas en la toma de decisiones comerciales y operacionales.

A continuación, se describen las bancas mencionadas anteriormente:

- Banca personal: ofrece productos y líneas de crédito de consumo y libre inversión a personas, como tarjetas de crédito, crédito de vehículo, crédito de libranza, crédito de libre inversión, etc.

- Banca agropecuaria: su portafolio de productos cubre las necesidades de financiación de actividades agrícolas, pecuarias, 
forestales, acuícolas y pesqueras. En el portafolio hay tarjetas de crédito, sobregiros, cupos, créditos asociativos, etc.

- Banca de microfinanzas: sus productos financieros de fácil acceso son acordes con las necesidades de familias, microempresarios y personas de bajos ingresos. Entre los productos que ofrece hay tarjetas de crédito, microcréditos, créditos para núcleos solidarios y créditos para grupos solidarios.

- Banca empresarial: orienta sus productos a satisfacer las necesidades de empresas, con líneas de crédito especializadas. En el portafolio de esta banca hay tarjetas de crédito, cupo rotativo, líneas de créditos para el financiamiento de operaciones de comercio exterior, etc.

- Banca oficial: los productos de su portafolio permiten la financiación de proyectos de infraestructura, salud y educación. Dirigido a entes territoriales, municipios, gobernaciones, empresas industriales y comerciales del Estado, corporaciones del sector público, sociedades de economía mixta y en general todas las empresas del sector oficial. En este portafolio hay créditos de libranza, créditos para la financiación de proyectos productivos y de infraestructura, entre otros productos.

Por otra parte, las gerencias regionales son dependencias en las que se ha dividido la gestión del proceso de crédito, de acuerdo a la zona geográfica en la que tiene presencia el banco. En cada zona geográfica hay recurso humano asignado a las bancas anteriormente mencionadas.

\section{El proceso de gestión de crédito del ban-} co: el proceso de gestión de crédito en el banco comprende los siguientes pasos: originación o venta del crédito, radicación de documentos, análisis de crédito, constitución de garantías y desembolso.

La originación o venta del crédito es realizada por la fuerza comercial, sobre todo desde las oficinas del banco, aunque también cuenta con otros canales para conseguir clientes que requieran crédito como eventos especiales (ferias como Agroexpo) o suscripción de convenios entre el banco y entes territoriales, fondos regionales y federaciones, entre otros. La originación comienza con la entrevista al potencial cliente, para establecer con claridad sus necesidades, su actividad económica y con base en esto, determinar qué línea de crédito puede ofrecerle el banco.

Posteriormente, se realiza la consulta del cliente potencial en listas inhibitorias y en centrales de riesgo, para limitar las relaciones comerciales con personas naturales o jurídicas que estén catalogadas como narcotraficantes o terroristas o con historia crediticia y comercial que no se ajuste a los niveles de riesgo tolerado por el banco. Una vez se ejecuten estas actividades, se informa al cliente potencial los documentos requeridos para acceder al crédito y se acuerda con este cuáles serán las garantías que respaldarán el crédito.

La radicación de documentos inicia cuando el cliente potencial entrega todos los documentos necesarios para acceder al crédito, para que estos sean revisados en cuanto a completitud y calidad. Luego, son digitalizados y asociados al trámite creado en el sistema. 
El análisis del crédito comprende el análisis técnico (revisión de la viabilidad del proyecto productivo) y financiero. La constitución de la garantía dependiendo del tipo de crédito que se requiera otorgar comprende la actividad de avalúo, que permite al banco identificar el valor comercial que se le da a un inmueble al momento de su realización, y la actividad de estudio de títulos, para acreditar el dominio sobre un bien raíz por parte del cliente potencial.

El desembolso comprende las actividades para asegurar la consistencia de la información de los documentos, verificar todas las condiciones de aprobación y la disponibilidad de recursos y, finalmente, desembolsar el crédito solicitado.

Actualmente, en el banco no hay indicadores de eficiencia y productividad que guíen la toma de decisiones y que reflejen el desempeño real de cada una de las bancas de crédito y sus zonas geográficas, solo se cuenta con indicadores de productividad relacionados con el recurso humano; de esta manera se evidencia la necesidad de contar con una metodología robusta para controlar y monitorear el desempeño del proceso de gestión de crédito del banco.

\section{Metodología}

Respecto a la metodología seleccionada para obtener las respuestas a las preguntas de esta investigación, en la literatura hay enfoques de frontera que permiten obtener medidas de eficiencia y que se agrupan en métodos paramétricos y no paramétricos (Berrío-Guzmán \& Muñoz-Santiago, 2005, p. 4), entre los cuales están el Modelo de Frontera Estocástico (Sto- chastic Frontier Approach, SFA), Análisis Envolvente de Datos (Data Envelopment Analysis, DEA) y Free Disposal Hull (FDH).

Cada uno de estos enfoques tiene tanto fortalezas como limitaciones y su utilización depende del objeto de estudio y del criterio de la persona que los aplica. Para el presente trabajo se seleccionó el modelo no paramétrico DEA, porque no requiere conocer de manera previa la distribución de los datos ni la función de costo y porque genera los valores exactos de las ineficiencias encontradas.

Partiendo del hecho de que para el banco objeto de estudio, sus carteras o segmentos de crédito son unidades estratégicas de negocio que se especializan en productos y/o mercados objetivos que establecen sus propios planes tácticos [alineados con el plan estratégico del banco], que tienen un presupuesto específico asignado y que son autónomas en la toma de decisiones comerciales y operacionales; se establece que para obtener los indicadores de eficiencia relativa objeto de esta investigación, la metodología a aplicar es DEA, pues adicionalmente a lo ya enunciado permite considerar múltiples variables de entrada y de salida con unidades de medida diferentes (Du, Liang, Yang, Bi \& Yu, 2010, p. 363) y adicionalmente permite obtener un solo indicador para cada unidad analizada.

Data Envelopment Analysis (DEA): el análisis envolvente de datos es una herramienta de programación lineal no paramétrica que permite obtener indicadores relativos de eficiencia y productividad mediante la comparación de las diferentes unidades de toma de decisiones estudiadas o DMU [Decision Making Units] y 
aporta un solo indicador en términos porcentuales pero ante la presencia de múltiples entradas y salidas, mediante la generación de una frontera eficiente conformada por las Unidades eficientes. DEA es una herramienta no paramétrica pues el modelo no requiere ninguna hipótesis sobre la distribución de los datos de estudio (Sekhri, 2011, p. 53). Permite analizar datos ordinales [que siguen algún tipo de orden] o nominales [que no tienen ningún orden y que toman valores mutuamente excluyentes] (Ruiz-Mondaca, 2008, p. 46).

Entre las ventajas del DEA se pueden enunciar (Rodríguez-Lozano, 2011, p. 67):

- Permite conocer las DMU más eficientes en términos relativos, es decir, en comparación con las otras DMU del modelo, y las que requieren una mayor intervención y atención para mejorar su desempeño.

- Permite conocer en qué medida esas DMU son eficientes o ineficientes.

- Permite contar con indicadores globales por DMU, que contemplen el uso de múltiples recursos de entrada (insumos) y salidas (productos) de diferente índole, sin que se requiera tener índices individuales por cada unidad de medida [pesos, horas, personas, etc.].

- Permite apoyar el proceso de toma de decisiones de la alta dirección, con indicadores claros y sencillos de interpretar, que guíen esta labor.

DEA parte de la medida universal de eficiencia (Cooper, Seiford \& Tone, 2000, p. 1):

Salida / Entrada
Considerando un conjunto compuesto por $n$ DMU denotadas como $\operatorname{DMU}_{\mathrm{j}}(\mathrm{j}=1, \ldots, \mathrm{n})$, las cuales utilizan recursos $x_{i j}(i=1, \ldots, m)$ y generan $s$ salidas $\mathrm{y}_{\mathrm{rj}}(\mathrm{r}=1, \ldots, \mathrm{s})$, y partiendo de que los multiplicadores $v_{\mathrm{i}}, u_{\mathrm{r}}$ asociados con $i$ entradas y $r$ salidas respectivamente son conocidos; entonces, teniendo en cuenta la anterior medida convencional, la eficiencia $e_{j}$ de $\mathrm{DMU}_{\mathrm{j}}$ se puede expresar como la proporción (ratio) de los pesos de las salidas y los pesos de las entradas, así:

$$
\sum_{r} \bar{u}_{r} y_{r j} / \sum_{r} \bar{v}_{i} x_{i j}
$$

En DEA, hay dos modelos básicos que se diferencian por la clase de retornos a escala considerados. Según la teoría de la producción, hay tres diferentes tipos de rendimientos a escala, que hacen referencia a las variaciones en la producción cuando los recursos de entrada varían en determinada proporción; se habla de rendimientos a escala decrecientes, cuando la producción aumenta en menor proporción en comparación con el aumento de los recursos de entrada o inputs. Por el contrario, los rendimientos a escala crecientes se presentan cuando la producción aumenta en una proporción mayor al aumento de los recursos de entrada o inputs; también puede haber rendimientos constantes a escala cuando al aumentar los factores de producción o entradas, la producción aumenta en la misma proporción.

Ya hablando de los modelos básicos de DEA específicamente, por una parte, está el modelo CRS (Constant Returns to Scale) para los retornos a escala constantes, llamado inicialmente 
CCR en honor a sus creadores Abraham Charnes, William W. Cooper y Edwardo Rhodes, quienes en su artículo Measuring the Efficiency of Decision Making Units (1978) dan a conocer este modelo; por la otra, está el modelo VRS (Variable Returns to Scale) para los retornos a escala variable, también conocido como BCC también en honor a sus creadores Rajiv D. Banker, Abraham Charnes y William W. Cooper, quienes después de 6 años de trabajo partiendo del primer modelo logran sacarlo a la luz académica (Banker, Charnes \& Cooper, 1984).

\section{Modelo CRS}

Específicamente, si la $\mathrm{DMU}_{0}$ está bajo estudio, este modelo está dando la solución del problema de programación fraccional para la medida de eficiencia de esa $\mathrm{DMU}_{0}$ así (Rodríguez-Lozano, 2011, p. 74):

$$
e_{o}=\max \sum_{r} u_{r} y_{r o} / \sum_{i} v_{i} x_{i o}
$$

Sujeto a:

$$
\begin{gathered}
\sum_{r} u_{r} y_{r j}-\sum_{r} v_{i} x_{i j} \leq 0, \text { para todo } j \\
u_{r}, v_{i} \geq \varepsilon, \text { para todo } r, i
\end{gathered}
$$

Donde $\varepsilon$ es un valor no- arquimidian designado estrictamente positivo.

Aplicando la teoría de programación fraccionaria expresada en Abraham Charnes y William W. Cooper (1962, p. 67) y realizando los siguientes cambios de variables: donde:

$$
t=\left(\sum_{i} v_{i} x_{i o}\right)^{-I}
$$

El problema inicial puede ser transformado en el siguiente modelo de programación lineal:

$$
e_{o}=\max \sum_{r} \mu_{r} y_{r o}
$$

Sujeto a:

$$
\begin{gathered}
\sum_{i} v_{i} x_{i o}=1 \\
\sum_{r} \mu_{r} y_{r j}-\sum_{i} v_{i} x_{i j} \leq 0, \quad \forall j \\
\mu_{r}, v_{i} \geq \varepsilon \text { para todo } r, i
\end{gathered}
$$

Dado que los retornos a escala son constantes, se genera una frontera como la que se muestra en la gráfica 1 , en la cual las unidades C y E son eficientes.

$$
\mu_{r}=t u_{r} \mathrm{y} v_{i}=t v_{i}
$$




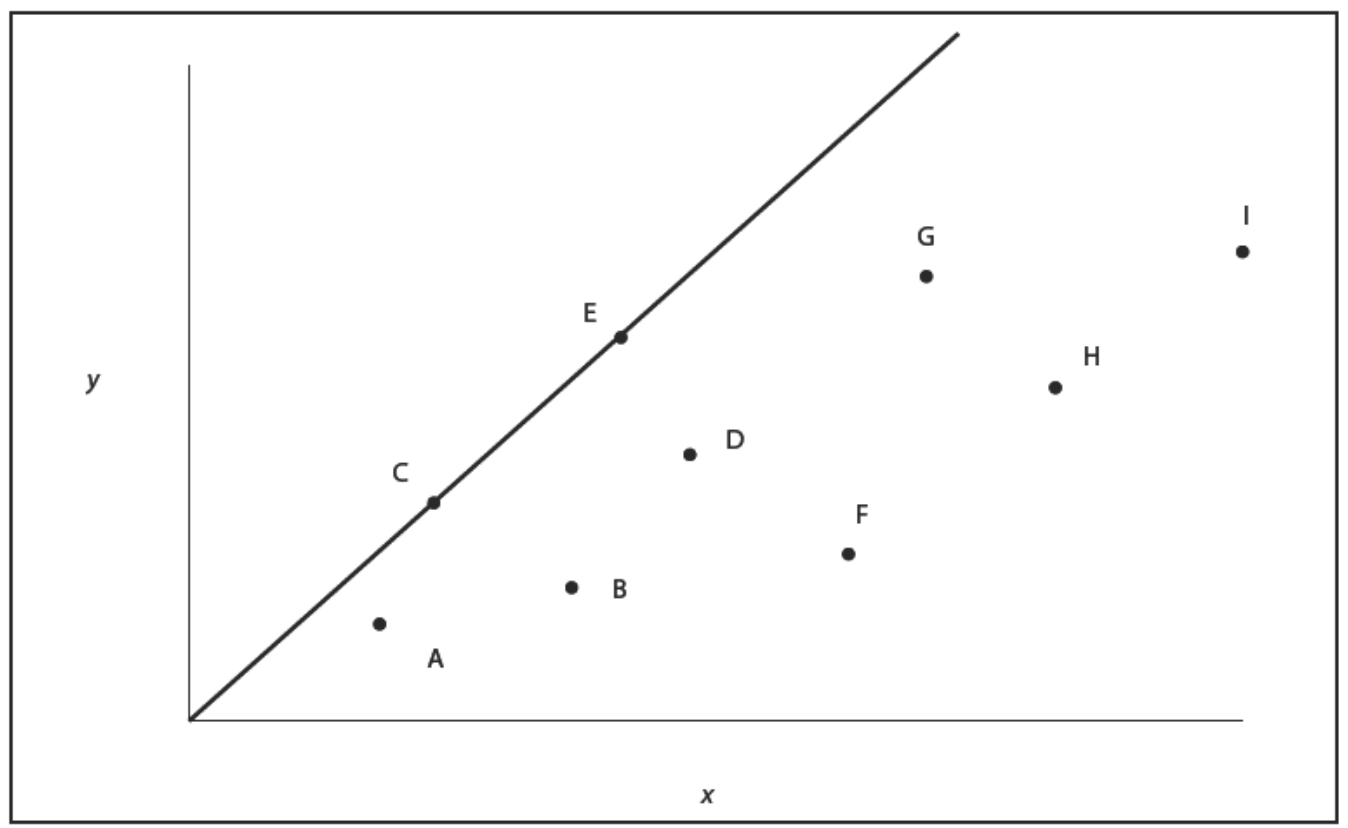

Gráfica 1

Frontera CRS

Fuente: Gloria Isabel Rodríguez-Lozano (2011, p. 75)

\section{Modelo VRS}

Retomando todos los parámetros anteriores, para este modelo se tiene como planteamiento matemático (Rodríguez-Lozano, 2011, p. 76):

$$
e_{o}^{*}=\max \left[\sum_{r} u_{r} y_{r o}-u o\right] / \sum_{i} v_{i} x_{i o}
$$

Sujeto a:

$$
e_{o}^{*}=\max \sum_{r} \mu_{r} y_{r o}-\mu_{o}
$$

Sujeto a:

$$
\begin{aligned}
& \sum_{r} v_{i} x_{i o}=1 \\
& \sum_{r} \mu_{r} y_{r j}-\mu_{o}-\sum_{i} v_{i} x_{i j} \leq 0, j=1, \ldots, n
\end{aligned}
$$

$\mu_{r} \geq \varepsilon, \quad v_{i} \geq \varepsilon, \quad \forall i, r$

$\sum_{r} u_{r} y_{r j}-u_{o}-\sum_{i} v_{i} x_{i j} \leq 0, \quad j=1, \ldots, n$

$$
\mu_{o} \text { irrestricta }
$$

$u_{r} \geq \varepsilon, \quad v_{i} \geq \varepsilon, \quad \forall i, r$

$u_{o}$ no restringida en signo

Dado que los retornos a escala son constantes, se genera una frontera como la que se muestra en la gráfica 2 , en la cual las unidades A, C, E, G e I son eficientes.

Con su equivalente en programación lineal: 
Adicionalmente, cada uno de estos modelos puede estar orientado a las entradas o a las salidas. Si dentro del estudio realizado es posible minimizar la utilización de los recursos y no es fácil modificar las salidas, se escogerá un modelo orientado a las entradas. De otra manera, si lo que se puede modificar son las salidas y no es posible variar los recursos, entonces se optará por un modelo orientado a las salidas. En las siguientes cuatro gráficas se ilustra lo anteriormente dicho.

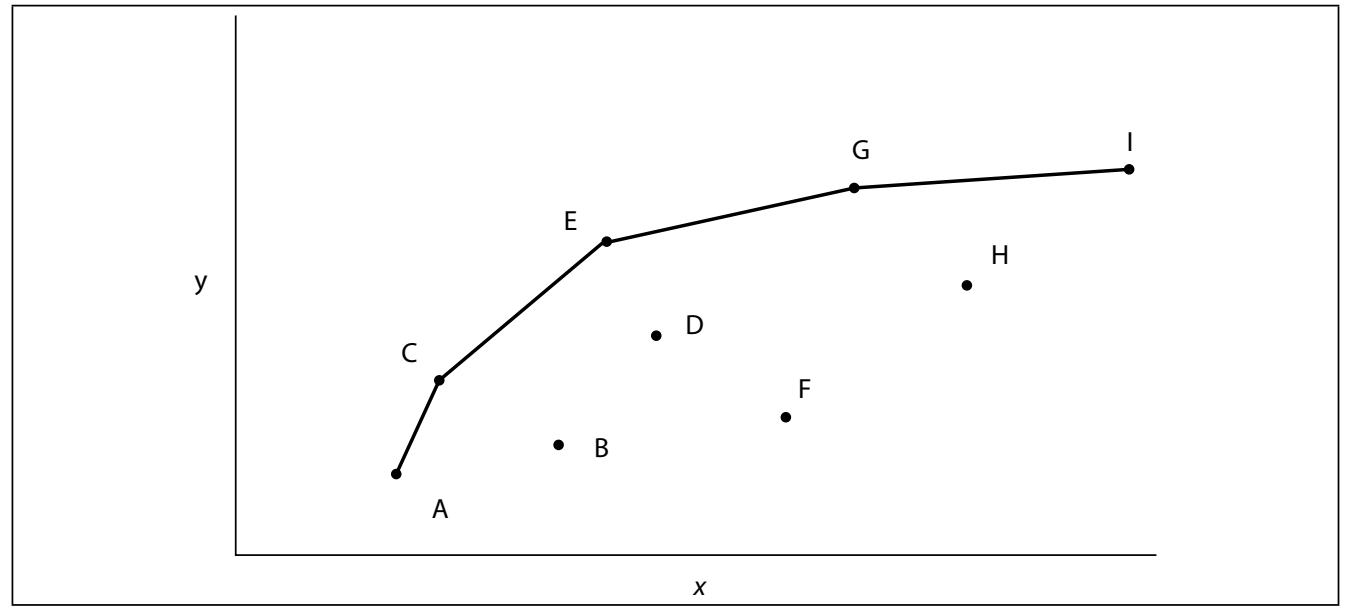

Gráfica 2

Frontera VRS

Fuente: Gloria Isabel Rodríguez-Lozano (2011, p. 77)

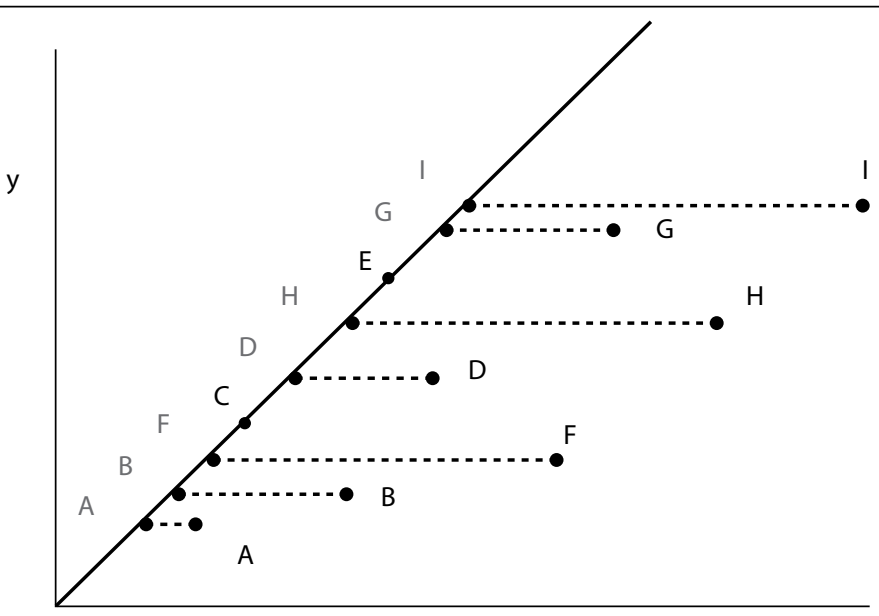

\section{Gráfica 3}

Frontera CRS - orientada a las entradas

Fuente: Gloria Isabel Rodríguez-Lozano (2011, p. 81) 


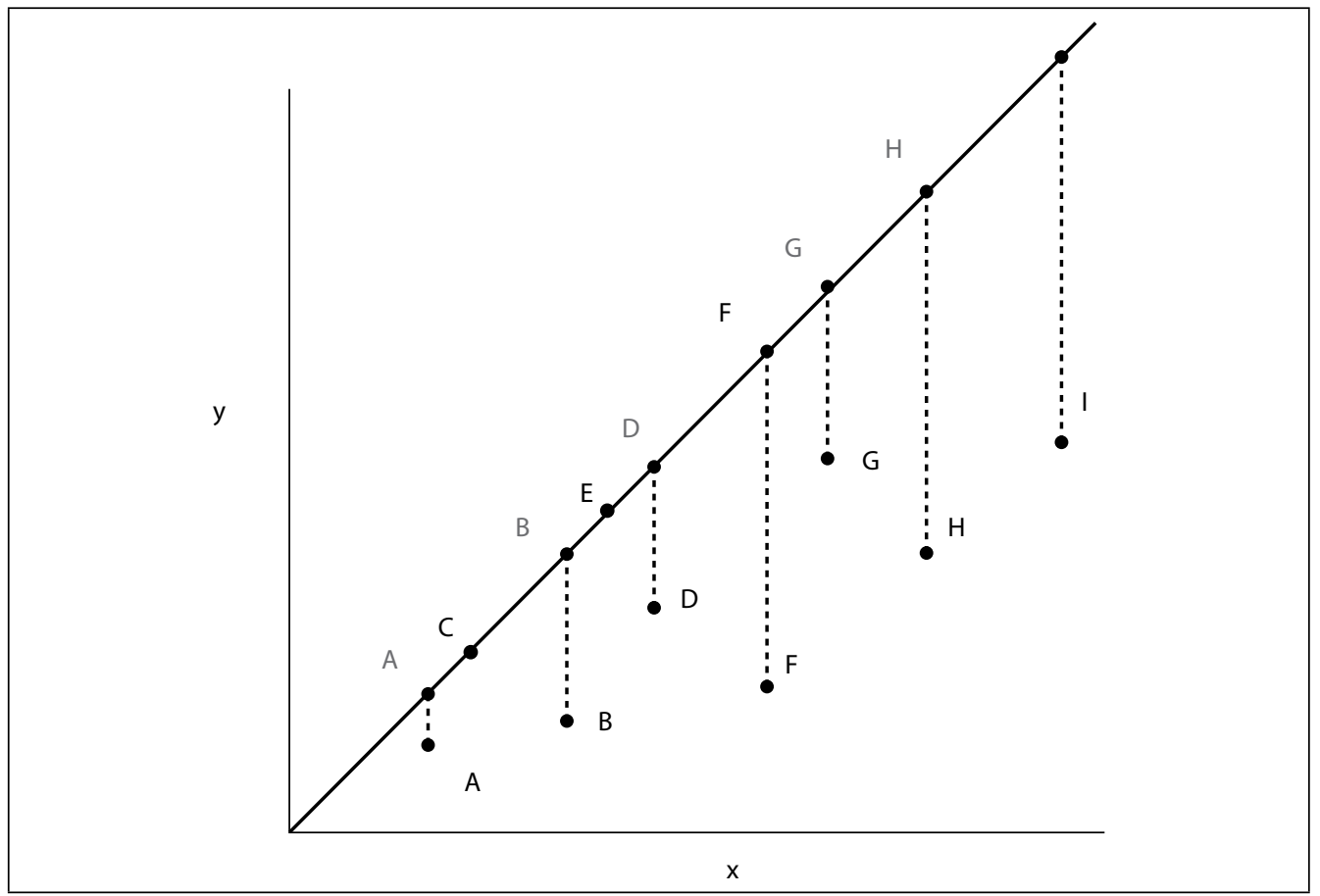

Gráfica 4

Frontera CRS - orientada a las salidas

Fuente: Gloria Isabel Rodríguez-Lozano (2011, p. 82)

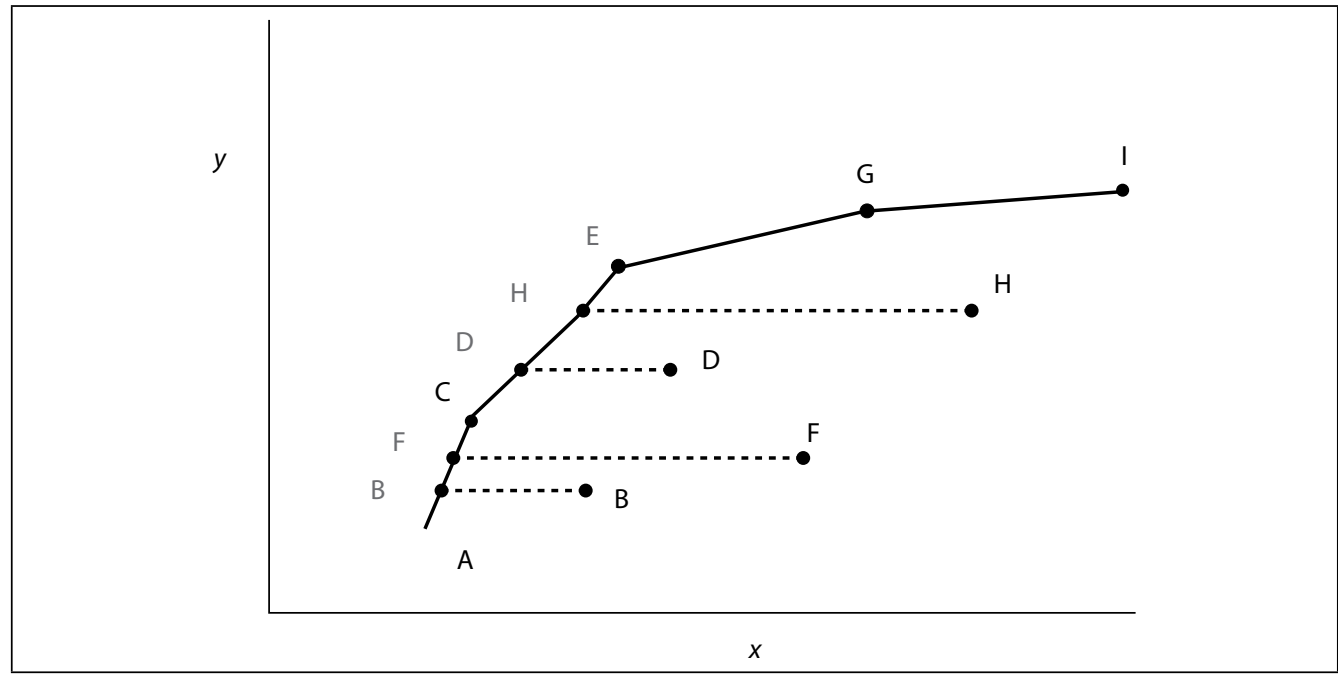

Gráfica 5

Frontera VRS - orientada a las entradas

Fuente: Gloria Isabel Rodríguez-Lozano (2011, p. 79) 


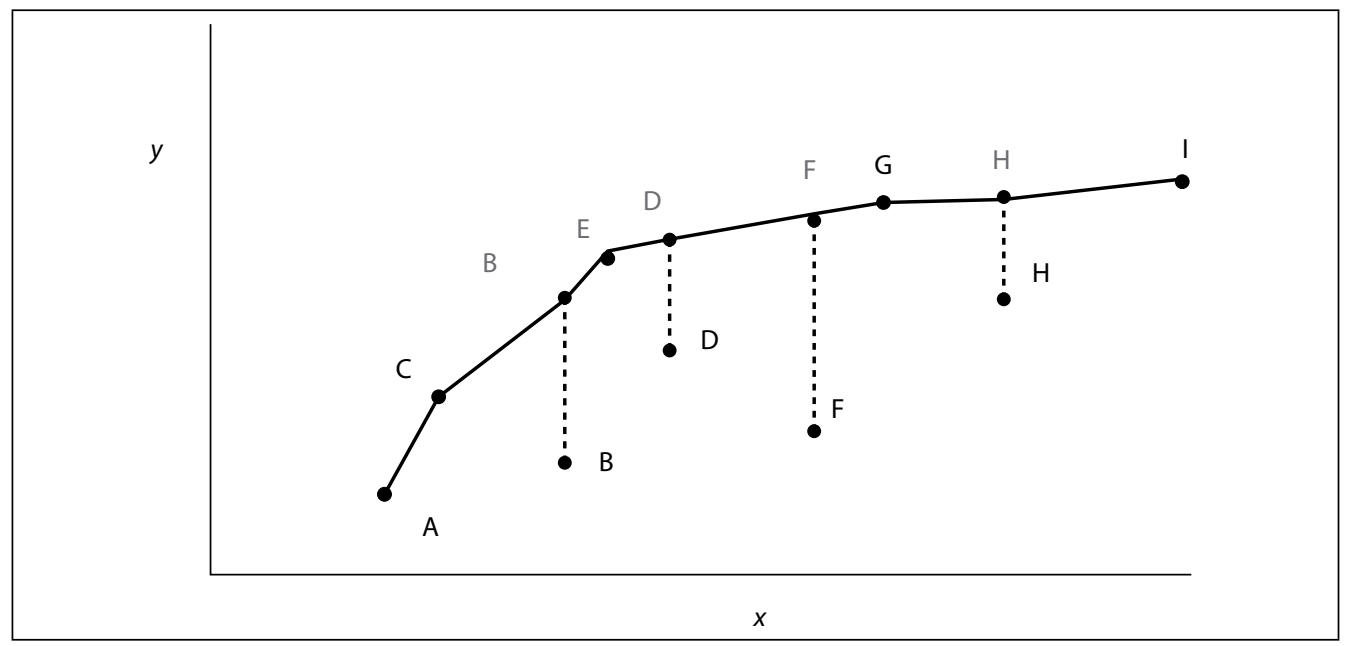

Gráfica 6

Frontera VRS - orientada a las salidas

Fuente: Gloria Isabel Rodríguez-Lozano (2011, p. 80)

Revisión de la literatura actual: hay una extensa variedad de literatura concerniente a la aplicación de modelos DEA, tanto para el sector real como para el sector financiero; sin embargo, no hay investigaciones enfocadas en el proceso de gestión de crédito bancario; en general, los autores comparan la eficiencia en diferentes bancos sin centrarse en procesos específicos. Entre los trabajos actuales y de interés para esta investigación están los referidos a continuación.

Otro trabajo reciente de la aplicación DEA en el sector financiero lo hace Zuzana Svitálková (2014, p. 646), en esta investigación compara la eficiencia del sistema bancario en varios países de la Unión Europea [República Checa, Eslovaquia, Austria, Polonia, Hungría y Eslovenia], haciendo uso de modelos DEA con retornos a escala variables (VRS) y constantes (CRS). Este estudio considera solo bancos comerciales y fue realizado para el período comprendido entre 2004 y 2011. Toma como variables de en- trada costos de personal, depósitos y activos fijos; define las variables de salida como ingresos netos por intereses, créditos totales y provisión de créditos incobrables. Como resultado, el trabajo muestra que el mejor rendimiento lo tiene el sector bancario austriaco y checo, en contraposición a los sistemas bancarios de Eslovenia y Eslovaquia que son los más ineficientes.

Otro estudio reciente con modelos DEA corresponde a Jolly Puri y Shiv Prasad Yadav (2014, p. 6421) para el sector bancario de la India; ellos proponen un modelo DEA con salidas no deseadas (como los anteriores autores) y un modelo DEA difuso considerando que los datos de las variables de entrada y de salida no siempre están disponibles de manera exacta, es decir, son imprecisos (difusos).

En México, Rodrigo Gómez-Monge (2013), en su trabajo doctoral Medición de la eficiencia de las bancas comercial y de desarrollo con la metodología DEA (Data Envelopment Analysis), a 
partir de los procesos de internacionalización del sistema bancario en México, estudia la eficiencia para 15 bancos (dos de ellos públicos), entre 2004 y 2008. Como variables de entrada, toma cinco: depósitos corrientes de ahorradores, depósitos a plazo de ahorradores, capital contable, gastos operativos y activos fijos. Como variables de salida utiliza la utilidad neta, préstamos personales, préstamos corporativos y comerciales, seguros comerciales y derivados fundamentados en ingreso y otros activos. Utiliza el modelo de supereficiencia DEA, orientado a salidas y considerando rendimientos variables a escala. En los resultados del estudio se expone que nueve de los quince bancos analizados son eficientes, y los bancos restantes están por fuera de la frontera eficiente.

El modelo de supereficiencia DEA, usado en esta investigación fue formulado por Per Andersen y Niels Christian Petersen (1993, p. 1262), perfeccionado por Paul W. Wilson (1995, p. 31) y Úrsula Faura-Martínez, Juan Cándido Gómez-Gallego, María Concepción Pérez-Cárceles y Juan Gómez-García (2012, p. 360). Este modelo se caracteriza por eliminar la restricción que hace que los puntajes de eficiencia se limiten a 1 (100\%), por cuanto una o más DMU pueden tener una eficiencia (más bien supereficiencia), mayor a 1 (100\%).

En la investigación titulada Análisis envolvente de datos: estimación de la eficiencia técnica y asignativa del sector bancario nicaragüense, periodo 2008-2011, Ricardo José Canales-Salinas (2013, p. 78) realiza la medición de eficiencia entre seis (6) bancos. El autor selecciona como variables de entrada número de empleados, bienes de uso o capital físico y fondos prestables.
Como variables de salida selecciona las colocaciones totales, conformadas por la cartera de crédito y las inversiones en valores utilizando el modelo CCR para estimar la eficiencia técnica global y el modelo BCC para estimar la eficiencia técnica pura.

En Colombia, recientemente se han realizado trabajos de medición de la eficiencia en el sector bancario, entre los cuales están los dos que se detallan a continuación:

1. Nueva evidencia sobre la eficiencia de la banca colombiana: una medición con modelos de frontera no paramétricos (Sarmiento, Cepeda, Mutis \& Pérez, 2013, p. 12), en este trabajo los autores evalúan la eficiencia de 23 bancos comerciales entre 2000 y 2009 utilizando los modelos CCR y BCC orientados a entradas y orientados a salidas. Se plantean dos entradas (depósitos y costos totales) y dos salidas (inversiones y cartera en créditos), para el análisis de la eficiencia técnica y para el análisis de eficiencia de costos se plantean tres entradas (capital laboral, capital financiero y capital físico) y dos salidas (inversiones y créditos ofrecidos).

El documento también expone la utilización del método de ventanas, para la medición de la eficiencia técnica, en el que se evaluaron 33 ventanas temporales diferentes de dos años cada una. Como resultado del estudio, los autores establecen el incremento de la eficiencia bancaria y al mismo tiempo una alta heterogeneidad de las medidas de eficiencia entre las DMU analizadas; adicionalmente, presentan el incremento de la eficiencia técnica en entidades 
financieras que efectuaron fusiones y adquisiciones.

2. Eficiencia de los establecimientos bancarios (EB): una aproximación mediante modelos DEA (Pirateque, Piñeros \& Mondragón, 2013, p. 9). En este documento, los autores analizan la eficiencia del sistema bancario colombiano entre 2000 y 2012 y encontraron que las entidades de capital nacional son más eficientes que las de capital extranjero. La selección de DMU comprende 18 establecimientos bancarios que fueron comparados mediante el modelo BCC orientado a salidas.

En resumen, luego de la revisión de literatura reciente tanto internacional y latinoamericana como colombiana, hay casos similares en cuanto al estudio de la eficiencia en bancos, la utilización de modelos BCC orientados a salidas, la determinación de entradas relacionadas con costos, número de empleados, número de sucursales y la selección de salidas relacionadas con créditos vigentes, créditos morosos, inversiones y utilidad neta.

Como resultado de la revisión de literatura internacional, resalta la inclusión de salidas no deseadas en los modelos, como la cartera morosa. Otro tema importante es la utilización de variaciones al modelo básico DEA, como modelos con salidas imprecisas o difusas no deseadas, mediciones de la eficiencia en dos etapas, técnica de eficiencia cruzada y supereficiencia, entre otras.

De manera contraria al objetivo del presente trabajo, en los documentos revisados se estudia la eficiencia entre diferentes bancos, pero ninguno compara la eficiencia entre las bancas y zonas geográficas de una misma entidad financiera.

Desde otro ángulo, en 2004, Gholamreza Jahanshahloo, Alireza Amirteimoori y Sohrab Kordrostami, en su trabajo Measuring the MultiComponent Efficiency with Shared Inputs and Outputs in Data Envelopment Analysis, determinan la eficiencia de 31 sucursales bancarias localizadas en ocho (8) ciudades de Irán. Primero, los autores realizan un análisis de eficiencia DEA con un enfoque de DMU multicomponente (Jahanshahloo, Amirteimoori \& Kordrostami, 2004, p. 288); posteriormente, miden la eficiencia agrupando las sucursales de acuerdo con su designación en la organización; como espectro temporal del estudio toman el primer semestre de los años 2000 y 2001. Consideran ocho (8) variables: cantidad de personal, cantidad de computadores, espacio en metros cuadrados, número de clientes, monto de depósitos, cantidad de préstamos, prima y monto de satisfacción de clientes. Adicionalmente, consideran dos (2) componentes: ventas y servicios, que comparten recursos. El documento concluye por una parte que el método aplicado sirve en situaciones reales en las que la gerencia ve los procesos de producción como un proceso multietapa. Por otra parte, explica que la segregación de las DMU en componentes facilita la toma de acciones por parte de la gerencia únicamente en los componentes ineficientes.

Alireza Amirteimoori y Reza A. Nashtaei (2006, p. 16) realizan otro estudio similar que aplica los conceptos anteriormente expuestos. En este documento, los autores miden el progreso y retroceso de las DMU (28 sucursales bancarias ubicadas en 3 ciudades de Irán) y 
sus subunidades en los seis primeros meses de 2003 y 2004. En la construcción del modelo, los autores toman siete variables: cantidad de computadores y personal, como entradas; depósitos, préstamos, primas, utilidades y monto de satisfacción de cliente, como salidas. También se consideran tres componentes: depósitos, ventas y servicios. No todas las salidas son producidas por los tres componentes.

Por otro lado, Chuang-Min Chao, MingMiin Yu y Mu-Chen Chen, en Taiwán, aplican el modelo DEA convencional y un modelo DEA multiactividad para doce (12) holdings financieros en 2004, que utilizan algunos insumos compartidos. La finalidad del estudio es medir la eficiencia relativa global de los holdings y la eficiencia relativa de las diferentes filiales (Chao, Yu \& Chen, 2010, p. 813). Las actividades que estudian son banca, valores, seguros y otros. No todos los holdings financieros realizan todas las actividades.

Respecto a la definición de entradas y salidas, los autores utilizan entradas y salidas exclusivas para cada actividad y entradas compartidas. Por ejemplo, para banca se definen como entradas los gastos de mano de obra, gastos financieros y gastos no financieros; para seguros se definen como entradas mano de obra y costo de capital y el "equity". Por otro lado, se definen como entradas en común para banca y valores, el número de sucursales y gastos no operativos.

En cuanto a las salidas, en el documento, los autores definen: préstamos e ingresos no financieros para banca; ganancias por inversiones e ingresos por intereses más el resultado del corretaje para valores; suma de comisiones y otros ingresos (incluyendo comisiones de suscripción y resultados por operaciones financieras) para seguros e ingresos operativos de todas las filiales. Como conclusión, presentan que el modelo DEA multiactividad - a diferencia del modelo convencional- posee una mayor capacidad de identificar fuentes de ineficiencia, lo que a su vez brinda un mayor conocimiento para implementar mejoras organizativas focalizadas.

De acuerdo a lo expuesto en estos últimos trabajos, se infiere que hay otras variaciones de los modelos tradicionales DEA utilizados para comparar la eficiencia relativa entre DMU de diferentes organizaciones y de una misma organización siempre y cuando se conozca su estructura, que es necesaria para definir el modelo multiactividad.

Igualmente, se infiere que estos modelos permiten reconocer dentro del planteamiento del problema recursos de entrada o salidas que puedan ser compartidas por las DMU, lo cual es una manera más realista, detallada y focalizada de identificar las ineficiencias. Estos modelos DEA no tradicionales también se aplican en diferentes procesos de una organización o en diferentes líneas de negocio.

Para el presente trabajo, el objeto de estudio está delimitado de tal manera que se estudia solamente una línea de negocio (crédito) y un proceso (colocación de créditos); a diferencia de otros trabajos, las sucursales bancarias no son tomadas como DMU.

\section{Delimitación del modelo DEA específico:} para delimitar en su totalidad un modelo DEA, es necesario definir las unidades de toma de decisiones (DMU) objeto de estudio que cumplan las siguientes características: deben ser homogéneas, es decir, que tomen el mismo tipo de 
recursos de entrada y deben generar el mismo tipo de salidas. A continuación, se determinan las entradas (inputs) y las salidas (outputs) del modelo y se establece el horizonte temporal del estudio. Paso seguido se selecciona el tipo de modelo de acuerdo a los retornos de escala y si este se orienta a entradas, a salidas o sin ninguna orientación.

Definición de las DMU: para el presente trabajo se han seleccionado cuarenta (40) DMU conformadas por cinco bancas, cada una dividida en ocho zonas geográficas. Esta definición se

\begin{tabular}{|c|c|c|}
\hline Banca & $\begin{array}{c}\text { Zonas } \\
\text { geográficas }\end{array}$ & Sigla \\
\hline \multirow{8}{*}{ Personal } & Antioquia & PERANTQ \\
\hline & Bogotá & PERBTA \\
\hline & Cafetera & PERCAFE \\
\hline & Costa & PERCOST \\
\hline & Occidente & PEROCCI \\
\hline & Oriente & PERORI \\
\hline & Santanderes & PERSAN \\
\hline & Sur & PERSUR \\
\hline \multirow{8}{*}{ Agropecuaria } & Antioquia & AGROANTQ \\
\hline & Bogotá & AGROBTA \\
\hline & Cafetera & AGROCAFE \\
\hline & Costa & AGROCOST \\
\hline & Occidente & AGROOCCI \\
\hline & Oriente & AGROORI \\
\hline & Santanderes & AGROSAN \\
\hline & Sur & AGROSUR \\
\hline \multirow{8}{*}{ Microfinanzas } & Antioquia & MICROANTQ \\
\hline & Bogotá & MICROBTA \\
\hline & Cafetera & MICROCAFE \\
\hline & Costa & MICROCOST \\
\hline & Occidente & MICROOCCI \\
\hline & Oriente & MICROORI \\
\hline & Santanderes & MICROSAN \\
\hline & Sur & MICROSUR \\
\hline
\end{tabular}

realiza atendiendo a la estructura organizacional del banco, en la cual existen dos vicepresidencias: la de banca comercial que contiene a su vez la banca empresarial y oficial; y vicepresidencia de banca agropecuaria, que contiene las bancas personal, microfinanzas y agropecuaria. Y en la jerarquía, dependiendo de estas vicepresidencias están las gerencias regionales.

Para una fácil identificación y mejor manejo de la información, a cada DMU le fue asignada una sigla que será utilizada a lo largo del trabajo, como muestra la tabla 1.

\begin{tabular}{lll}
\hline \multirow{2}{*}{ Banca } & \multicolumn{1}{c}{ Zonas } & \multicolumn{1}{c}{ Sigla } \\
& geográficas & \\
\hline \multirow{4}{*}{ Empresarial } & EMPRAia & EMPRBTA \\
& Cafetera & EMPCAFE \\
& Occidente & EMPCOST \\
& Oriente & EMPOCCI \\
& Santanderes & EMPORI \\
& Sur & EMPSAN \\
& Antioquia & OFIANTQ \\
& Bogotá & OFIBTA \\
& Cafetera & OFICAFE \\
Costa & OFICOST \\
& Occidente & OFIOCCI \\
& Oriente & OFIORI \\
& Santanderes & OFISAN \\
& Sur & OFISUR \\
\hline
\end{tabular}

Tabla 1

DMU por banca y zonas geográficas

Fuente: elaboración propia 


\section{Entradas (inputs)}

Son recursos que utilizan las DMU para realizar sus procesos de transformación. Las entradas seleccionadas son:

- Presupuesto programado (en millones de pesos): esta entrada hace referencia a la cantidad de dinero de que se dispone para la ejecución de las actividades del proceso de gestión de crédito de las DMU. El presupuesto es asignado por la junta directiva del banco anualmente, dependiendo de los resultados (objetivos y metas alcanzadas) y el porcentaje de ejecución del presupuesto del año inmediatamente anterior. El presupuesto anual programado se discrimina de manera mensual.

- Cantidad de asesores comerciales por zona geográfica (en número): se refiere al número de trabajadores que conforman la fuerza comercial, pertenecientes a cada DMU, que se encargan de originar y radicar la operación de crédito.

- Horas hombre trabajadas en la operación del proceso de gestión de crédito (número de horas): esta entrada hace referencia al número de horas trabajadas al mes, del personal que conforma la parte operativa del proceso de gestión de crédito (diferentes a los asesores comerciales), y que ejecutan las acciones de verificación de documentos, análisis de crédito, constitución de garantías y desembolso.

\section{- Cantidad de oficinas por zona geográfi-} ca (en número): se refiere a la cantidad de sucursales físicas con las que cuenta cada una de las DMU en cada zona geográfica en donde tiene cubrimiento.

\section{Salidas (outputs)}

Representan el resultado que cada DMU genera, luego de utilizar las entradas en sus procesos de transformación. Las salidas consideradas para el presente trabajo son las siguientes:

- Valor de desembolsos (en millones de pesos): se refiere al monto total en pesos, de los créditos desembolsados.

- Cantidad de desembolsos (en número): se refiere al número de créditos que han sido otorgados y desembolsados.

La notación que se utiliza para identificar las cuatro entradas y las dos salidas es la siguiente:

- Presupuesto programado (en millones de pesos): PREPROG

- Cantidad de asesores comerciales por zona geográfica (en número): ASECOME

- Horas hombre trabajadas en la operación del proceso de gestión de crédito (número de horas): HRSHOTR

- Cantidad de oficinas por zona geográfica (en número): OFIREG

- Valor de desembolsos (en millones de peSOS): DESPESOS

- Cantidad de desembolsos (en número): DESNUM

Horizonte temporal de estudio

Teniendo en cuenta la disponibilidad de los datos, el horizonte temporal es el año 2013.

Tipo de modelo DEA

Su selección se fundamenta en la falta de evidencia sobre la existencia única de retornos constantes a escala, de tal manera que el modelo VRS 
contempla la posibilidad de la existencia de retornos a escala - constantes, crecientes y decrecientes-, que pueda tener cada una de las DMU estudiadas. El modelo estará orientado a las salidas, por cuanto se pretende identificar cuáles son las DMU eficientes que logran maximizar el nivel de las salidas manteniendo la utilización de los recursos disponibles. Se determinó la orientación a salidas por la rigidez que presenta el banco por ser un banco oficial, en cuanto a realizar modificaciones importantes a los recursos de entrada en el proceso de crédito.

\section{Resultados}

Los índices de eficiencia de cada DMU por cada mes del año en estudio se presentan en la tabla 2 , se observan las unidades eficientes $(100 \%)$ y las ineficientes (con valores menores a 100\%). El mes con mayor número de DMU eficientes fue febrero, con 15; en contraposición, los meses con menor número de DMU eficientes fueron mayo y agosto con 7 DMU. Los índices que aparecen como $0,0 \%$, realmente son valores muy pequeños cercanos a 0 .

La tabla 3 muestra de manera resumida las unidades que fueron eficientes en todos los meses del año y la tabla 4, las 14 unidades que nunca fueron eficientes.

A continuación, la tabla 5 muestra las unidades que deben tomar como referencia cada una de estas 14 unidades para lograr ubicarse en la frontera eficiente.

\section{Eficiencia por bancas}

Los resultados de los niveles totales de eficiencia muestran que las bancas con los mejo- res resultados son la agropecuaria y la oficial; mientras que la banca personal obtiene los peores (gráfica 7).

Adicionalmente, las unidades que más contribuyen a que la mejor banca sea la agropecuaria son las ubicadas en la zona cafetera y en la zona sur, pues la primera es eficiente durante todos los meses y la segunda tiene un índice del 95\% en el único mes en que no es eficiente.

Ahora bien, respecto al número de unidades eficientes, de nuevo, oficial y agropecuaria ocupan los primeros lugares (gráfica 8).

\section{Eficiencias por zona geográfica}

$\mathrm{Al}$ analizar los índices totales de eficiencia, las Zonas Geográficas con mejores resultados son la sur y la cafetera. La zona geográfica con los peores resultados es la costa (gráfica 9).

Adicionalmente, la unidad que más contribuye a que la mejor zona geográfica sea la sur es banca agropecuaria, pues es eficiente durante once meses y en el único mes que no lo es tiene un índice del 94,7\%. Ahora bien, respecto al número de unidades eficientes, las mismas zonas geográficas - cafetera y sur-ocupan los primeros lugares (gráfica 10). 


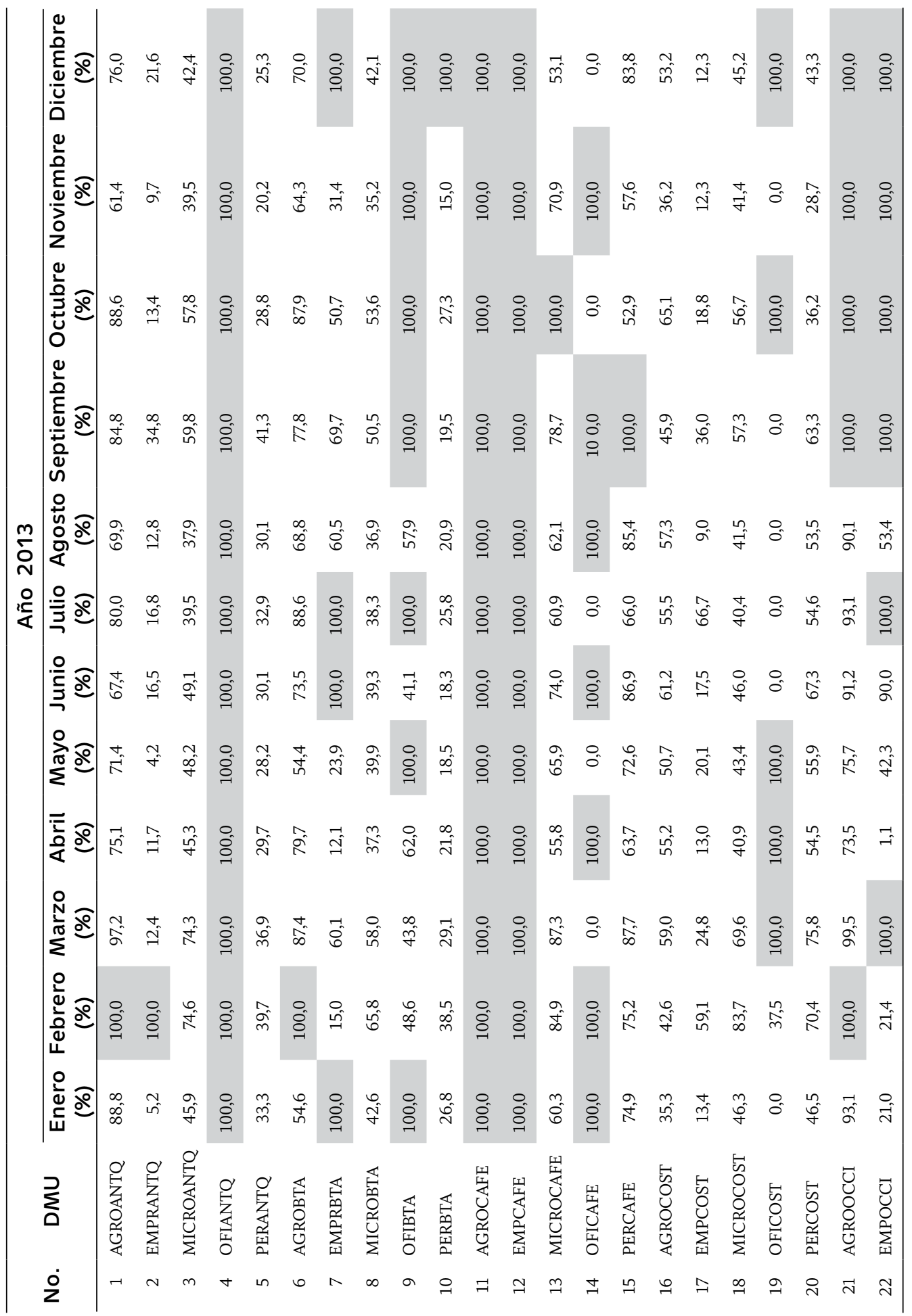




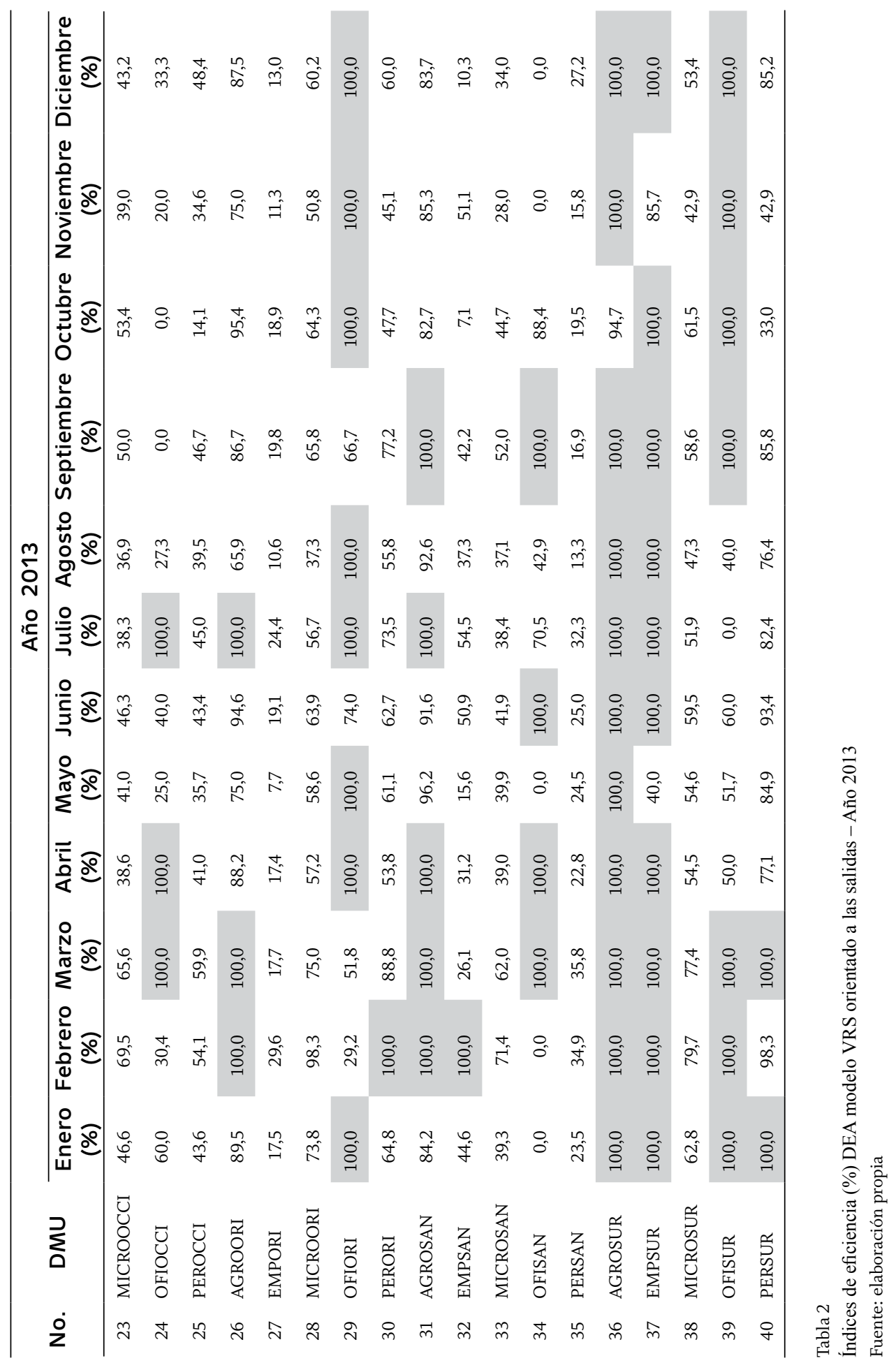


34 / VOL. 17/ NO. 43/ ENERO-JUNIO 2016

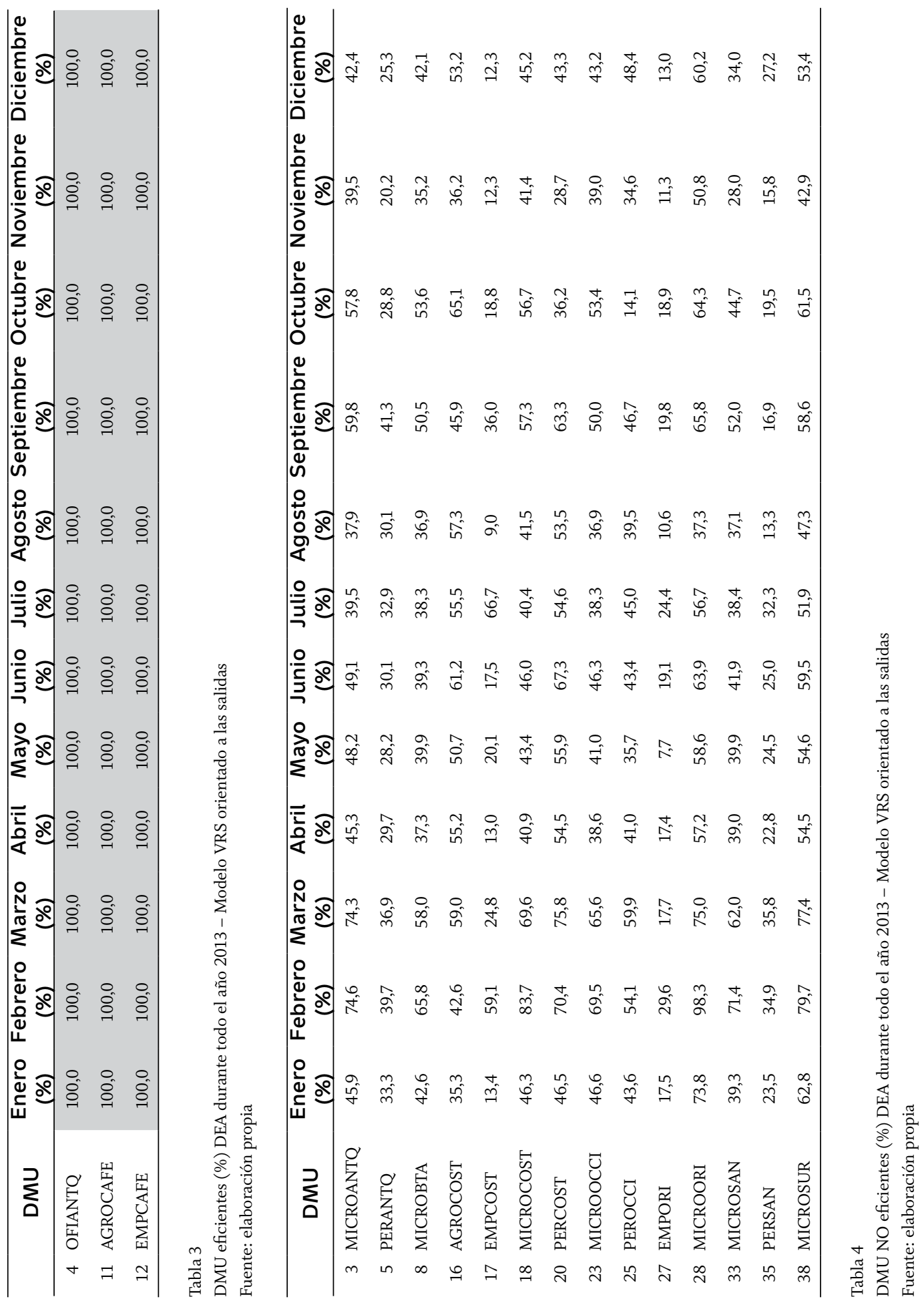


INDICADORES DE EFICIENCIA RELATIVA DEL PROCESO dE GESTIÓN DE CRÉdITO / s. SÁNCHEZ, G. ROdRícuez / 35

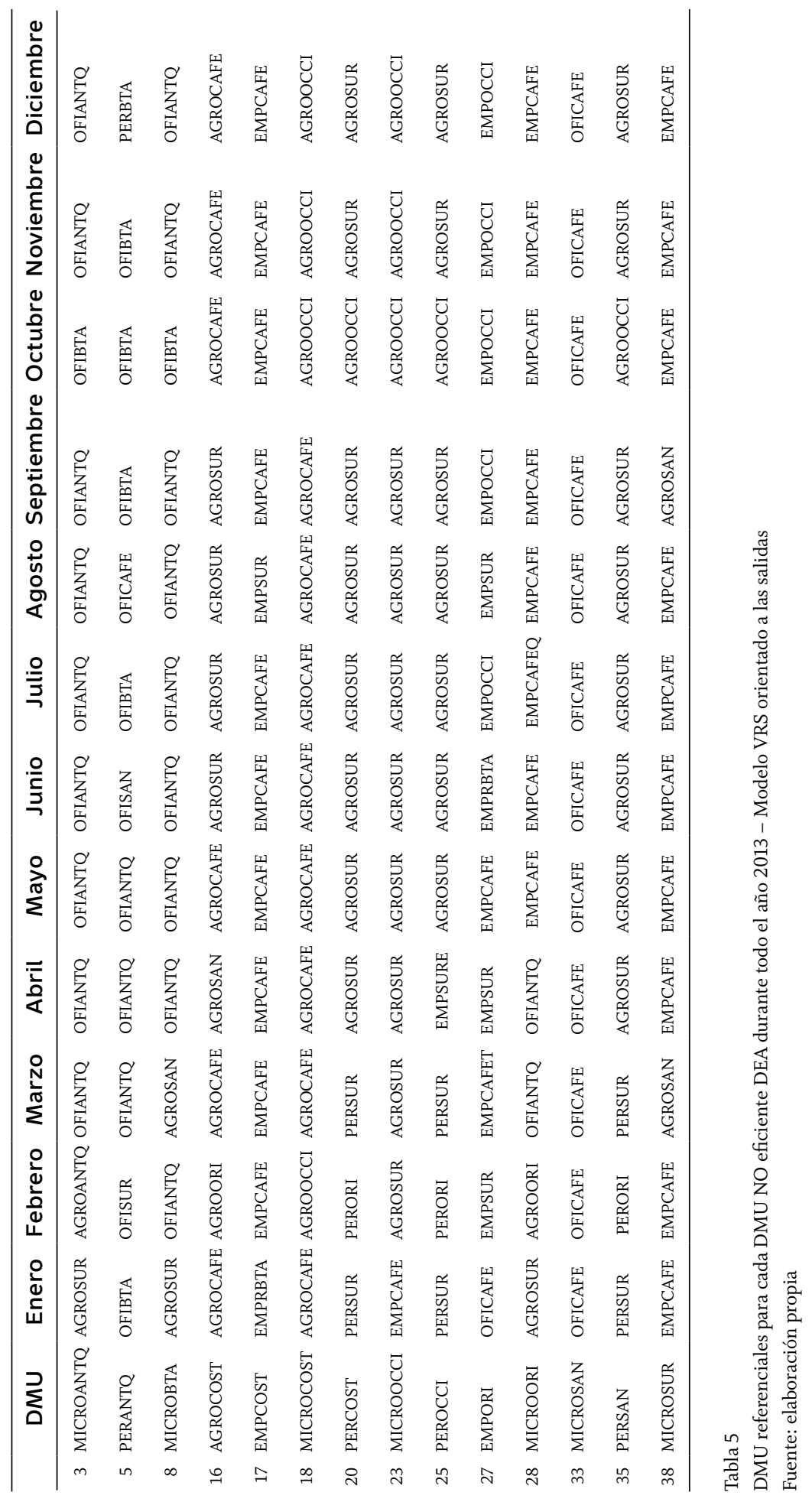




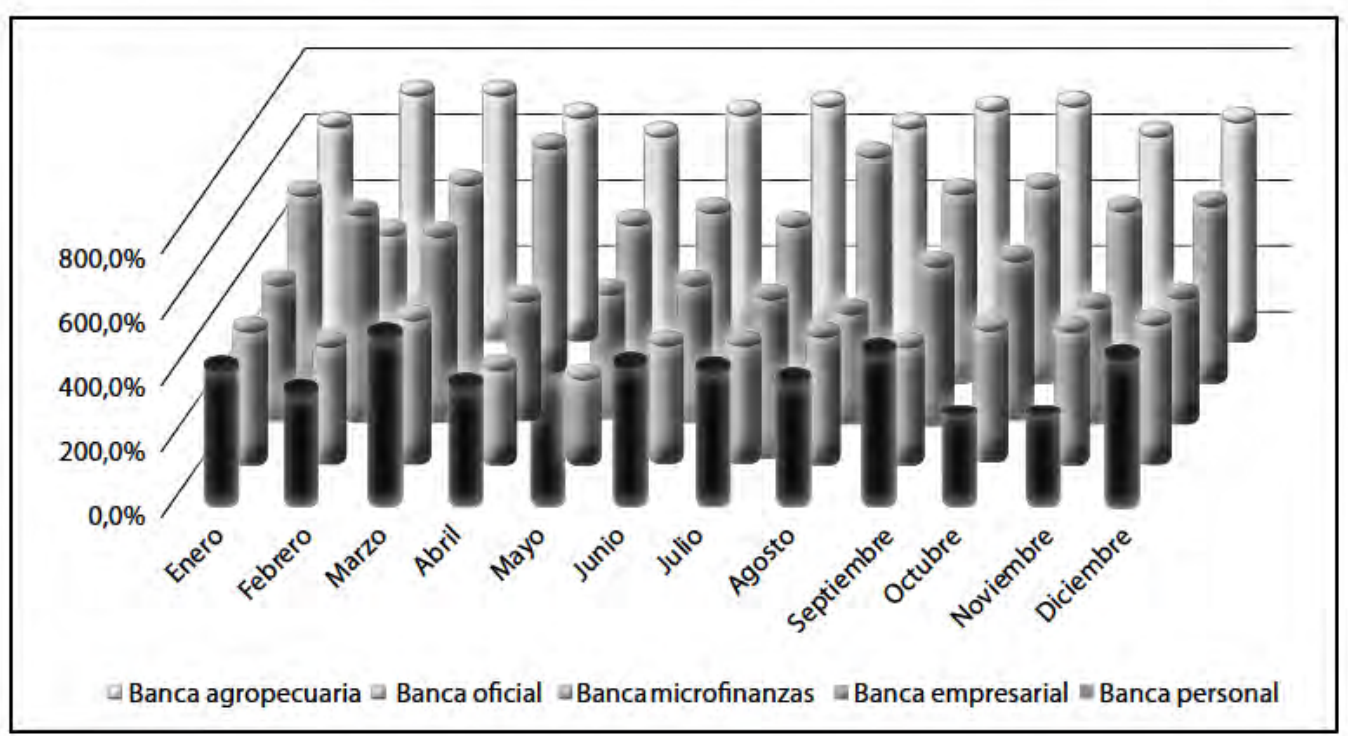

Gráfica 7

Eficiencia por bancas

Fuente: elaboración propia

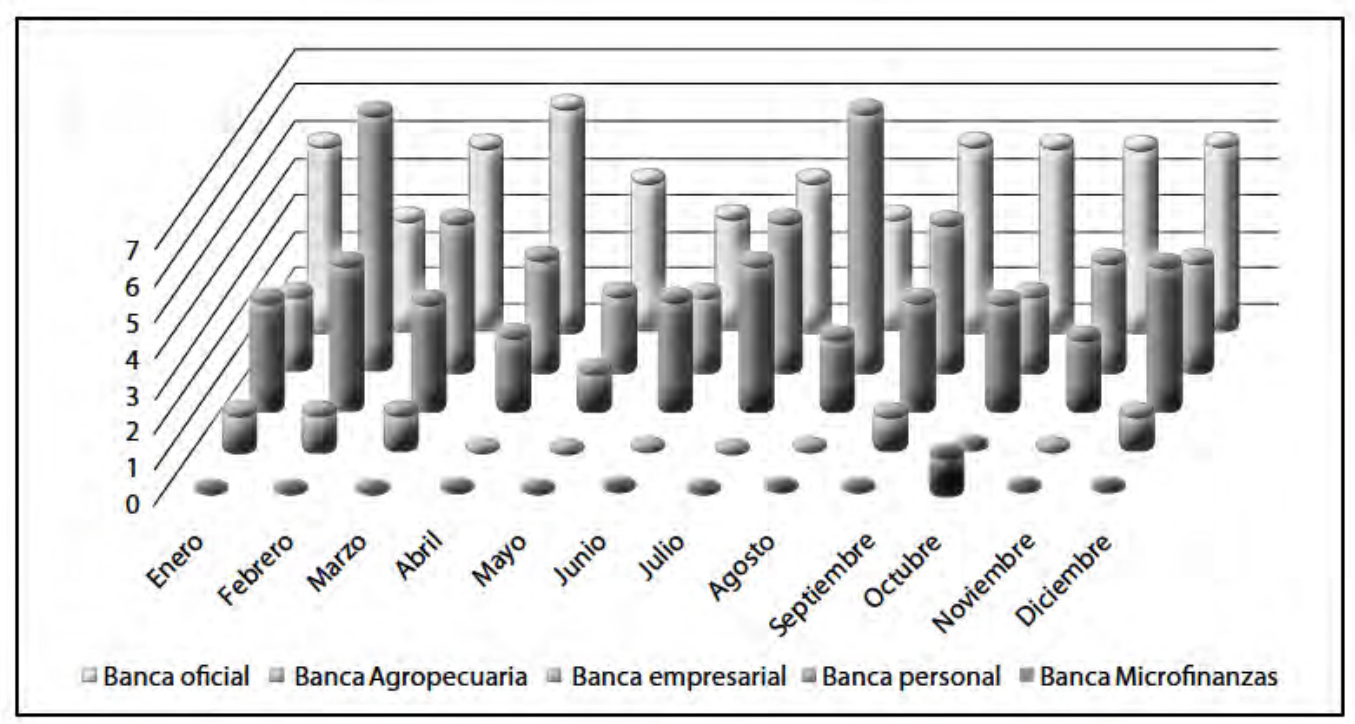

\section{Gráfica 8}

Número de unidades eficientes por banca

Fuente: elaboración propia 
INDICADORES DE EFICIENCIA RELATIVA DEL PROCESO DE GESTIÓN DE CRÉdITO/ S. SÁNCHEZ, C. RODRícueZ/ 37

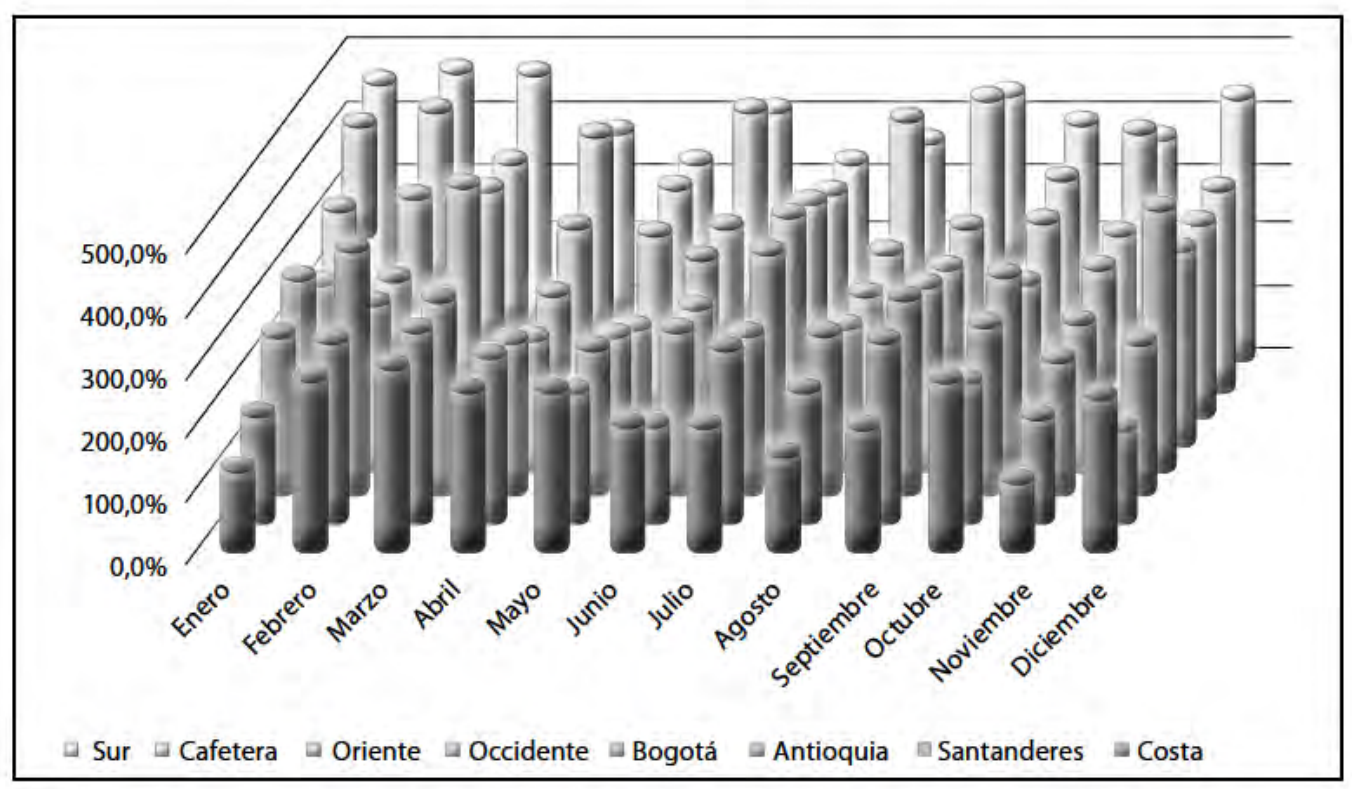

Gráfica 9

Eficiencia por zonas geográficas

Fuente: elaboración propia

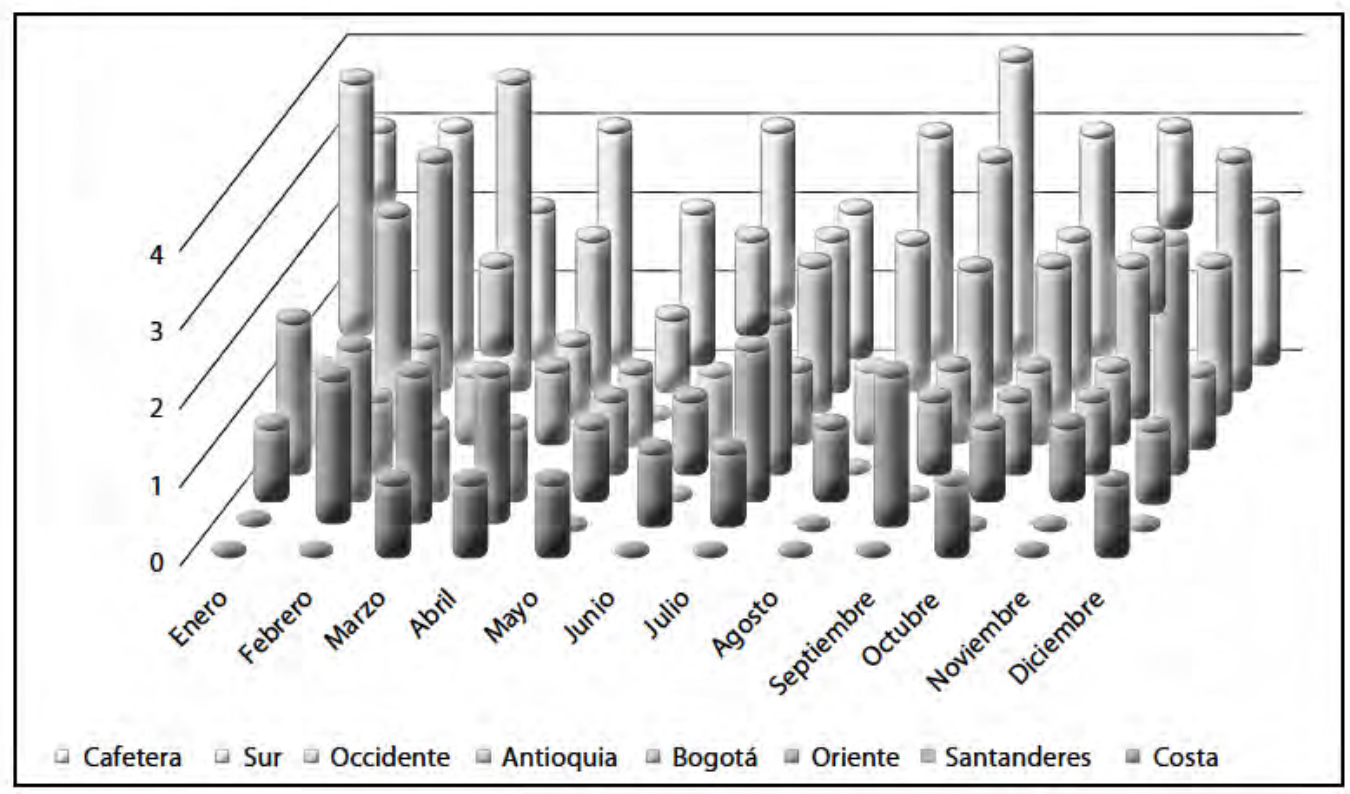

Gráfica 10

Número de unidades eficientes por zona geográfica

Fuente: elaboración propia 


\section{Conclusiones}

Respecto a los resultados arrojados por el modelo se concluye lo siguiente:

1. El análisis envolvente de datos (DEA) de un total de 40 DMU estudiadas en el proceso de gestión de crédito del banco en 2013, permitió obtener indicadores globales que midieran la eficiencia relativa de cada una de las DMU seleccionadas, incluyendo en el modelo variables de diferente índole y unidad de medida utilizadas como insumos y generadas como salidas de sus actividades de transformación.

2. Las bancas con mejor desempeño en cuanto a eficiencia son la agropecuaria y la oficial, la banca más ineficiente es la personal.

3. La banca con mejor desempeño en cuanto a número de veces que sus DMU fueron 100\% eficientes y mantuvieron índices de eficiencia cercados a $100 \%$ en el transcurso de 2013 fue la agropecuaria. Aunque las DMU de la banca oficial alcanzaron un mayor número de veces un índice de 100\% que las de la banca agropecuaria, su comportamiento se ve empañado por presentar en varios meses ineficiencias muy cercanas a $0 \%$.

4. Las zonas geográficas más eficientes fueron la sur y la cafetera; adicionalmente, sus DMU alcanzaron el mayor número de veces el 100\% de eficiencia durante el año analizado. La zona geográfica con peor desempeño es la costa.

5. De manera individual, se destacaron las DMU AGROCAFE, EMPCAFE, OFIANTQ que durante todo el año presentaron efi- ciencia del 100\%, y la DMU AGROSUR con índices de eficiencia de 100\% en once meses del año.

6. En contraposición a lo anterior, los meses con peor desempeño fueron mayo y agosto, debido a que solo siete DMU alcanzaron la eficiencia. Por otra parte, la banca con peor desempeño en cuanto a número de unidades eficientes en todo el año fue la de microfinanzas con solo una DMU eficiente en octubre. La zona geográfica más ineficiente fue la costa, con solo una DMU (OFICOST) eficiente en cinco meses del año. Por último, las DMU más ineficientes que deben mejorar su desempeño haciendo esfuerzos importantes son EMPORI, EMPRANTQ, PERSAN Y EMPCOST.

7. En cuanto a las implicaciones administrativas prácticas para el banco, se considera que el modelo definido en el presente trabajo es una buena forma de medir la eficiencia relativa entre las bancas y zonas geográficas de tal manera que se pueda monitorear y controlar su desempeño en el proceso de gestión de crédito.

8. Por otro lado, la metodología es fácilmente implementable y puede ser aplicada con regularidad siempre y cuando el área encargada de realizar la medición tenga acceso a información actualizada de las DMU por entradas y salidas. Se recomienda continuar con la medición para poder realizar más adelante análisis comparativos de eficiencia de las DMU, no solo entre diferentes períodos de un mismo año, sino también entre los mismos períodos de diferentes años, que permitan determinar sus mejoras o retroce- 
sos y los factores estacionales que impacten el desempeño de las DMU.

9. Adicionalmente, para futuras investigaciones, se propone incluir como entradas del modelo otros gastos y costos adicionales para cada DMU asociados con el proceso de gestión de crédito, ítems que en esta oportunidad no se pudieron tener en cuenta por falta de información. Así mismo, se propone incluir como salidas del modelo cartera vigente (en pesos) y cartera en mora (en pesos), para completar el ciclo de la gestión de crédito y cartera, máxime cuando la labor de colocación de una entidad financiera incluye la generación de préstamos y su cobro eficiente.

\section{Referencias}

Amirteimoori, Alireza \& Nashtaei, Reza A. (2006). The Role of Time in Multi-Component Efficiency Analysis: An Application. Applied Mathematics and Computation, 177 (1), 11-17. Disponible en: https://www. academia.edu/15169334/The_role_of_ time_in_multi-component_efficiency_ analysis_An_application

Andersen, Per \& Petersen, Niels Christian (1993). A Procedure for Ranking Efficient Units in Data Envelopment Analysis. Management Science, 39 (10), 1261-1264.

Banco Agrario de Colombia (2009). Informe de Responsabilidad Social. Bogotá: Banco Agrario de Colombia. Disponible en: https://www.bancoagrario.gov.co/ RelacionAccionistas/Documents/RSocial/ IRS_2009.pdf
Banco Agrario de Colombia (2013a). Estudio técnico y análisis de productividad. Bogotá: Vicepresidencia de Planeación y Desarrollo Corporativo, Gerencia de Ingeniería de Procesos y Mejora Continua.

Banco Agrario de Colombia (2013b). Informe de gestión. Disponible en: https://www. bancoagrario.gov.co/RelacionAccionistas/ Documents/Inf_gestion/IG_2013.pdf Banco Agrario de Colombia (2014a). Estatutos. Disponible en: http://www.bancoagrario. gov.co/acerca/Documents/estatutos.pdf Banco Agrario de Colombia (2014b). La entidad. Disponible en: http://www. bancoagrario.gov.co/acerca/Paginas/ Entidad.aspx

Banco de la República (2013). Reporte de la situación del crédito en Colombia - Marzo. Bogotá: Banco de la República. Disponible en: http://www.banrep.gov.co/es/node/31820

Banco de la República (2014). Reporte de estabilidad financiera - Marzo. Bogotá: Banco de la República. Disponible en: http://www. banrep.gov.co/es/node/35081

Banker, Rajiv D.; Charnes, Abraham \& Cooper, William W. (1984). Some Models for Estimating Technical and Scale Inefficiencies in Data Envelopment Analysis. Management Science, 30 (9), 1078-1092.

Berrío-Guzmán, Deisy \& Muñoz-Santiago, Alberto (2005). Análisis de la eficiencia relativa del sistema bancario en Colombia en el período 1993-2003 y propuesta estratégica de fortalecimiento. Pensamiento y Gestión: Revista de la División de Ciencias Administrativas de la Universidad del Norte, 18, 1-36. Disponible en: http://ciruelo. 
uninorte.edu.co/pdf/pensamiento_ gestion/18/1_Analisis\%20de\%20la\%20 eficiencia.pdf

Canales-Salinas, Ricardo José (2013). Análisis envolvente de datos: estimación de la eficiencia técnica y asignativa del sector bancario nicaragüense, periodo 20082011. Revista Electrónica de Investigación en Ciencias Económicas, REICE, 1 (1), 63-94. Disponible en: https://dialnet.unirioja.es/ descarga/articulo/5109443.pdf

Chao, Chuang-Min; Yu, Ming-Miin \& Chen, Mu-Chen (2010). Measuring the Performance of Financial Holding Companies. The Service Industries Journal, 30 (6), 811829.

Charnes, Abraham \& Cooper, William W. (1962). Programming with Linear Fractional Functionals. Naval Research Logistics Quarterly, 9 (3-4), 181-186.

Charnes, Abraham; Cooper, William W. \& Rhodes, Edwardo L. (1978). Measuring the Efficiency of Decision Making Units. European Journal of Operational Research, 2 (6), 429-444.

Cooper, William W.; Seiford, Lawrence M. \& Tone, Kaoru (2000). Data Envelopment Analysis: A Comprehensive Text with Models, Applications, References and DEA-Solver Software. Boston, Massachusetts: Kluwer Academic. Departamento Administrativo Nacional de Estadística, DANE (2014). PIB trimestral a precios constantes por ramas de actividad económica. Bogotá D.C. Disponible en: http://www.dane.gov.co/files/ investigaciones/boletines/pib/bol_PIB_ Itrime14.pdf
Du, Juan; Liang, Liang; Yang, Feng; Bi, GongBing \& Yu, Xiao-Bo (2010). A New DEABased Method for Fully Ranking all Decision-Making Units. Expert Systems, The Journal of Knowledge Engineering, 27 (5), 363-373.

Gómez-Monge, Rodrigo (2013). Medición de la eficiencia de las bancas comercial y de desarrollo con la metodología DEA (Data Envelopment Analysis), a partir de los procesos de internacionalización del sistema Bancario en México. Tesis doctoral, Instituto Politécnico Nacional, México. Disponible en: http://tesis.ipn.mx/jspui/ bitstream/123456789/13007/1/Tesis\%20 G\%C3\%B3mez\%20Monge\%20Rodrigo.pdf

Faura-Martínez, Úrsula; Gómez-Gallego, Juan Cándido; Pérez-Cárceles, María Concepción \& Gómez-García, Juan (2012). Comparación de rankings de eficiencia mediante análisis de componentes principales y DEA. Estadística Española, 54 (178), 357-373. Disponible en: http:// bddoc.csic.es: $8080 /$ detalles.html?id=71589 $3 \& \mathrm{bd}=\mathrm{ISOC} \& \mathrm{tabla}=\mathrm{docu}$

Jahanshahloo, Gholamreza; Amirteimoori, Alireza \& Kordrostami, Sohrab (2004). Measuring the Multi-Component Efficiency with Shared Inputs and Outputs in Data Envelopment Analysis. Applied Mathematics and Computation, 155 (1), 283-293. Disponible en: https://www.academia.edu/15169344/ Measuring_the_multi-component_ efficiency_with_shared_inputs_and_ outputs_in_data_envelopment_analysis 
Liang, Liang; Cook, Wade D. \& Zhu, Joe (2008). DEA Models for Two-Stage Processes: Game Approach and Efficiency Decomposition. Naval Research Logistics, 55, 643-653. Disponible en: http://www. deafrontier.net/papers/NRL_TwoStage.pdf

Pirateque, Javier E.; Piñeros, José H. \& Mondragón, Linda (2013). Eficiencia en los establecimientos bancarios (EB): una aproximación mediante modelos DEA. Borradores de Economía, 798, 1-39. Disponible en: http://www.banrep.gov.co/ es/borrador-798, http://www.banrep.gov.co/ sites/default/files/publicaciones/archivos/ be_798.pdf

Puri, Jolly \& Yadav, Shiv Prasad (2014). A Fuzzy DEA Model with Undesirable Fuzzy Outputs and its Application to the Banking Sector in India. Expert Systems with Applications, 41 (14), 6419-6432.

Rodríguez-Lozano, Gloria Isabel (2011). Indicadores DEA (Data Envelopment Analysis) de eficiencia y productividad para las actividades de extensión universitaria. Aplicación en la Universidad Nacional de Colombia. Bogotá: Centro Editorial, Universidad Nacional de Colombia, Facultad de Ciencias Económicas.

Ruiz-Mondaca, Erix Aldo (2008). Análisis de la eficiencia en la distribución de electricidad: una aproximación no paramétrica al caso peruano. Tesis de Licenciatura en Economía, Universidad Nacional del Callao, Lima.

Sarmiento, Miguel; Cepeda, Andrés; Mutis, Hernando \& Pérez, Juan F. (2013). Nueva evidencia sobre la eficiencia de la banca colombiana: una medición con modelos de frontera no-paramétricos. Archivos de Economía, Documento de trabajo, 392. Disponible en: https://colaboracion.dnp.gov. co/CDT/Estudios\%20Econmicos/392.pdf

Sekhri, Vidya V. (2011). A DEA and Malmquist Index Approach to Measuring Productivity and Efficiency of Banks in India. The IUP Journal of Bank Management, 10 (3), 49-64. Svitálková, Zuzana (2014). Comparison and Evaluation of Bank Efficiency in Selected Countries in EU. Procedia Economics and Finance, 12, 644-653. Disponible en: https://www.researchgate.net/ publication/275540997_Comparison and_Evaluation_of_Bank_Efficiency_in_ Selected_Countries_in_EU Wilson, Paul W. (1995). Detecting Influential Observations in Data Envelopment Analysis. Journal of Productivity Analysis, 6 (1), 27-45.

- Fecha de recepción: 5 de septiembre de 2015

- Fecha de aceptación: 3 de marzo de 2016

- Disponible en línea: 30 de junio de 2016

Para citar este artículo

Sánchez-Gooding, Sandra Paola \& Rodríguez-Lozano, Gloria Isabel (2016). Indicadores de eficiencia relativa del proceso de gestión de crédito en un banco colombiano, mediante análisis envolvente de datos (DEA). Cuadernos de Contabilidad, 17 (43), 13-41. http://dx.doi.org/10.11144/ Javeriana.cc17-43.ierp 
